\title{
Canciones y ritos de cumpleaños en Europa
}

\author{
Birthday songs and rites in Europe
}

\author{
Raquel FUENTES \\ (Universidad de Alcalá de Henares) \\ FUENTES_RL@hotmail.com \\ ORCID ID: 0000-0002-0139-6567
}

\begin{abstract}
I shall examine in this paper one of the RESUMEN: Este trabajo trata sobre una de las most widespread celebrations nowadays: birth-days. celebraciones más extendidas y actuales como la del We will approach it from the fields of anthropology cumpleaños, vista desde la antropología y el and folk studies, since it is a ritual which may provide folclore, pues se trata de un rito que puede aportar us with valuable information regarding syncretism. I información valiosa desde el punto de vista del shall address birthday celebrations origins, its nature sincretismo. Se aborda su origen, su carácter de rito as a rite of passage and the significance of birthday transicional y también la letra de su canción, song lyrics, including elements such as invitations, además de otros elementos, como las invitaciones, guests and gift-giving. invitados, regalos.
\end{abstract}

KEYWORDS: Birthday, ritual, syncretism, song, PALABRAS-ClAVE: cumpleaños, rito, sincretismo, passage canción, transición

Resulta curioso que una de las celebraciones más antiguas y vivas, extendidas a nivel mundial, haya pasado tan desapercibida en los estudios de carácter antropológico y folclórico; el motivo de ello, seguramente, lo encontremos en lo cotidiano de su presencia. El rito de cumpleaños merece bien un estudio en profundidad, si bien aquí solo podremos dar ciertas pinceladas, tanto por los escasos trabajos que existen sobre él como por su riqueza a nivel sincrético y lo mucho que dice de nosotros.

\section{EL ORIGEN DE LA CELEBRACIÓN DEL CUMPLEAÑOS}

La palabra «cumpleaños», tal y como señala J. Corominas y J. A. Pascual en su Diccionario etimológico, procede del latín y significa «llenar, completar». En el Diccionario de la Real Academia Española se define el término como «aniversario del nacimiento de una persona». Así también parece entenderse si consultamos la etimología de la palabra en sus diferentes voces (anniversaire de naissance, compleanno, birthday, natalicio...), y los diccionarios extranjeros como la Enciclopedia Universal Ilustradaamericana, que dice «Aniversario del día en que se ha nacido». Se puede entender, entonces, que el «cumpleaños» es el día en el que se completa un año de vida, sumándose a los ya vividos.

Desde una visión antropológica, interesa la definición de «cumpleaños» aportada por Funk y Wagnalls (1972), pues no solamente lo define como celebración del día en que uno nace, sino como una transición «entre un estado de ser y otro», lo que justifica el rito. Esta transición está marcada por el peligro (innato al cambio); tanto es así que señala que 
en este momento los espíritus, los buenos y malos, pueden interferir en la vida del homenajeado.

¿Quiénes celebraban el cumpleaños en épocas pasadas? La pregunta nos lleva al elemento principal del cumpleaños, a la astrología. No solo por la necesidad de tener un calendario para poder situar el día en que se nace y fijar así el día del aniversario, sino por su carácter vaticinador: conocida es la estrecha vinculación de emperadores y reyes con astrólogos que pronosticaban el tipo de personalidad que tendría el futuro gobernante e, incluso, su futuro, atendiendo a los astros y al momento del nacimiento.

Esta costumbre de origen pagano variaba en el grado de festejo y de los participantes, según la época y cultura en las que nos situemos. Observamos que en algunas civilizaciones la celebración se reducía casi exclusivamente a los emperadores (Antiguo Egipto) o reyes; mientras que en otras podía ser celebrada por grupos más numerosos (en Roma solo se permitía el festejo masculino).

Sobre la antigüedad, ya el historiador Herodoto contaba que los persas la consideraban la festividad más importante:

El aniversario de su nacimiento es de todos los días el que celebran con preferencia, debiendo dar en él un convite, en el cual la gente más rica y principal suele sacar a la mesa bueyes enteros, caballos, camellos y asnos, asados en el horno, y los pobres se contentan con sacar reses menores (Herodoto, 2000: 81).

Por otro lado, el carácter pagano de esta celebración y su rechazo en un principio por el cristianismo se hace evidente en la Biblia; en tres ocasiones se hace referencia a este aniversario de vida: el cumpleaños del Faraón de Egipto, el de Herodes y el del hijo de Job. En todas ellas se la vincula con la muerte: en el primero, el Faraón ahorca al jefe de los panaderos (G, 40, 20-23); en el segundo, Salomé pide a Herodes la cabeza de san Juan Bautista (Mt, 14, 5-11); y en el tercero, los hijos de Job son castigados con la muerte por celebrar el que parece ser el cumpleaños de su hermano mayor (Job, 1, 4-22). Como sabemos, más tarde la costumbre de la celebración del cumpleaños será cristianizada, festejándose incluso el nacimiento de Jesús, la Navidad. Anteriormente la fecha más relevante para los cristianos había sido la de la muerte, ya que, si la persona había tenido una buena conducta, pasaba a una mejor vida, por lo que esto último se consideraba digno de conmemorar. Algunas religiones, como la de los Testigos de Jehová, aún hoy no celebran la fecha del cumpleaños por considerarlo una festividad pagana.

\section{EL RITO DEL CUMPLEAÑOS: EL CUMPLEAÑOS COMO TRANSICIÓN. EL UMBRAL}

El cumpleaños está vinculado con la transición, de ahí la necesidad del rito. La transición simboliza el cambio, por lo que conlleva y connota peligro (al estar en un proceso de cambio entre un ser u otro o entre dos mundos, uno se expone a dejar de ser). Ambas significaciones las encontramos en el símbolo de la puerta y del umbral.

Ya en la antigua Roma existía un dios relacionado con las puertas, el dios Jano (en latín, janua, que derivaría a enero). Este dios está relacionado también con la astrología y el origen de todo; su carácter primigenio hizo que se le honrara como un dios de inicios, de comienzos; la puerta representa un medio de cambio, de transición y como tal posee la connotación de riesgo. Un ejemplo de ello son las grandes puertas de la Antigua Mesopotamia custodiadas por enormes animales con el fin de evitar la entrada de cualquier mal.

Esta perspectiva del Mundo Antiguo del inicio y de la transición - el umbralpuede aplicar también en el rito del cumpleaños, ya que se inicia el proceso de completar 
un nuevo año en cada aniversario: el cumpleañero en su día lo que hace realmente es abrir una puerta más, obtener un año más de vida, elemento que está bajo el poder divino. De esta manera, se puede afirmar que en el cumpleaños no solo existe una dimensión temporal (la de sumar años), sino también espacial: el niño o la niña, en su «viaje» (homo viator), va recorriendo un espacio en el que se le va pidiendo, exigiendo, cediendo y permitiendo ciertas acciones.

El espacio, así, es entendido como un camino en el que existen diferentes umbrales por los que el hombre va pasando a lo largo de su vida y por el que se va transformando. Esta visión de la realidad, que nos puede parecer muy lejana y que puede chocar con nuestra perspectiva actual, pervive aún en costumbres como la que encontramos en un pueblo de Guadalajara, en Almonacid de Zorita. Allí existe la costumbre de pasar por la puerta de la antigua muralla a los muertos antes de darles sepultura, viendo en este hecho una clara manifestación del símbolo de puerta como medio de transición.

¿Qué valor tiene el umbral? La dificultad de pasar el umbral no es la misma todos los años, pues depende del nivel de transformación y tramos alcanzados (por ejemplo, el paso a la vida adulta), hecho que repercute y se manifiesta en el grado de celebración. Uno de los cumpleaños más celebrados, por manifestar mayor cambio y ser inicio de una nueva etapa, es el festejo de los quince y dieciocho, que puede variar en edad, dieciséis o veintiuno; tiene que ver con los criterios culturales para considerar a una persona mayor de edad, y también en ocasiones, el género. En Sudamérica, por ejemplo, la fiesta de los quince años de las chicas tiene su correspondencia con el cumpleaños de los dieciocho de los chicos (menos festiva) debido, seguramente, al desajuste en la edad de madurez entre ambos sexos.

Uno de los países europeos que más celebra los quince años es la República Checa. Allí existe la costumbre de entregar al homenajeado «la cédula de ciudadanía». Respecto a la celebración de los dieciocho o veintiuno, hay países como Reino Unido y Australia en los que existe la tradición de entregar un objeto de gran valor simbólico: una llave, elemento que de nuevo nos recuerda al dios romano Jano y a la puerta.

De la información recogida en testimonios contemporáneos se desprenden otras celebraciones importantes: los cumpleaños que cierran una década, los cincuenta o la edad de jubilación e incluso los relacionados con número impar. A continuación, un testimonio de Rumanía:

Sí y es una fiesta muy importante. A la edad de un año o tres, tiene que ser un año impar, hay una costumbre muy interesante. Si se trata de un niño se le corta un poquito del pelo que se ata con una cinta, o se corta un poquitín de cuatros lados en forma de cruz digamos. La costumbre se llama «el corte del mechón» y éste se guarda en casa para siempre. Mi marido lo tiene todavía en una cajita. A los bebes no se les corta el pelo hasta la edad de un año justo para tener que cortar. Si se trata de una niña, encima de la cabeza se rompe un pan redondo especial casero que es un poco dulce, una «torta»; que se rompe en cuatro pedazos como la forma de la cruz y se da a los invitados a comer. ${ }^{1}$

En cualquiera de los casos, la madrina es la que lleva a cabo esta operación y el niño está sentado en una almohada alta. Justo después de este momento se coloca delante del homenajeado/a una bandeja en la que se ponen varios objetos: tijeras, estilográfica, dinero, libro, icono, espejo, etc. Últimamente ponen también un teléfono móvil, joyas, llaves del coche. El niño tiene que elegir tres objetos. Dicen que el primero que toca definirá su profesión. Si toca dinero será rico, etc. Con esta ocasión los padrinos compran

\footnotetext{
${ }^{1}$ En este rito la madrina actúa como mediadora, pues será la encargada de cortar el pelo y de romper el pan.
} 
ropa para el bebé y le visten. Mi madre me contó que a mí me rompieron la torta cuando tenía tres años y mi madrina me regaló unos pendientes de oro que llevé hasta la edad de 21 años, hasta que perdí uno en la bañera. Y lo sentí mucho. Era un recuerdo especial (Adriana Filip, Rumanía).

Podemos diferenciar tres fases en este rito: 1. Fase de paso, en la que el bebé se sitúa en una almohada alta (entre el cielo y la tierra). 2. Fase de separación (animismo), en la que se corta el primer mechón de pelo, en el caso masculino, o en la que se rompe un pan redondo en la cabeza para después comerlo, en el caso femenino (de esta manera contemplamos aquí dos interesantes símbolos: el cabello y el pan). Seguidamente, los padrinos traen ropa y visten al bebé o niño; es decir, le preparan para la nueva vida. Por último, 3. Fase de agregación: elección del objeto (tijeras, estilográfica, dinero, libro, icono, espejo, etc.), que determinará a qué se dedicará el niño.

Resulta interesante saber que en el Golfo de Guinea también existe la costumbre de invitar a los bebés a escoger un objeto entre varios, en este caso no para saber su profesión futura, sino para saber con quién de sus antepasados está vinculado, ya que los objetos pertenecen a familiares fallecidos.

Este pensamiento que relaciona a los bebés con espíritus protectores seguramente también esté vinculado a la celebración del cumpleaños, de hecho, también lo encontramos en Europa. Los griegos creían en un espíritu protector (daemon) que estaba vinculado con el dios que regía su nacimiento, y que tenía como finalidad cuidar del bebé durante toda su vida. De aquí derivaría, según señalan diferentes investigadores, la creencia del hada madrina, el ángel custodio, e incluso, el santo patrón. Esto explicaría, además, que en algunos países como Grecia sea más importante el día del santo que el del propio cumpleaños.

Muy parecido a la tradición rumana, que vimos antes, es la del siguiente rito búlgaro recogido por Rositsa Yósifova y José Manuel Pedrosa en Costumbres y fiestas del pueblo búlgaro:

Con la fiesta de la primera hogaza de pan que celebraba la llegada del recién nacido. [...] Esta hogaza era untada con miel, y todas las mujeres asistentes habían de probar un bocado de ella. La primera que lo tomaba era la parturienta, y todas las demás, después. Las migas que se desprendían habían de ser menuditas, para que los dientes del niño fueran también así. [...] Sobre una mesita baja se ponían muchos objetos cuya función era la de llamar la atención del niño. Estos objetos simbolizaban la profesión que el niño escogería. La criatura debía acercarse hasta esos objetos sin la ayuda de nadie [...]. Si escogía el libro, eso significaba que saldría estudioso; si escogía el bolígrafo, que sería escritor; si optaba por la moneda, que sería hombre de negocios... (2009: 21-22)

\section{SINCRETISMO. ELEMENTOS EN EL CUMPLEAÑOS}

La antigüedad y vigencia del rito de cumpleaños, junto a esa visión de peligro, lo convierte en un acto complejo y de gran valor sincrético; se genera a partir de ese miedo a cruzar el umbral que se desea pasar y en el que pueden actuar diferentes espíritus. Baste mencionar el cuento de La Bella durmiente, en el que encontramos además de la idea de espíritus protectores en el nacimiento de una persona (los daemon griegos que también estarán presentes en la cultura romana), el maleficio del hada que, al sentirse deshonrada por no ser invitada (llamada, venerada), actúa contra la niña, hechizándola y condenándola a morir cuando cumpla quince años (un umbral muy marcado y donde identificamos símbolos archiconocidos como la rueca o el hilo, que nos evocan a 
las Parcas romanas, a las Moiras griegas o a las Nornas de la mitología nórdica, relacionados todos ellos con la idea de transición y la muerte).

El trabajo de Bárbara Rinkoff aporta luz sobre algunos de los comportamientos y actos que se dan en la celebración del cumpleaños, y en el mismo cuento de La Bella Durmiente: afirma que el festejo del cumpleaños tenía como objetivo no verse dañado por los malos espíritus. ¿Cómo se lograba? Explica que para conseguirlo los seres queridos lo rodeaban a fin de que fuera protegido con sus buenos deseos y su presencia. Tanto los regalos como el banquete constituirían dos elementos que servirían para ganarse el favor de los espíritus buenos.

De esta forma, atendiendo a todo lo expuesto y como explicaremos a continuación, se debe entender el cumpleaños como un rito sincrético y atender a su estudio desde diferentes aspectos, como la astrología, la magia (debido a la creencia de los espíritus o hadas) e incluso desde la religión (temor al proceder de los dioses) o a la superstición.

En cuanto a la relación con la religión, debemos mencionar a Ralph y Adelin Linton, quienes, en su libro The Lore of Birthday, señalan que elementos como el de la vela o la torta —equivalente al pastel - ya figuraban en la Antigua Grecia. Según argumentan podría venir del homenaje a Artemisa, vinculada con el ciclo lunar, puesto que se le ofrecía una especie de torta redonda con velas. El fuego de las velas también era apagado con un soplido, para que el deseo que se había pedido la diosa lo concediera; el deseo viajaba en ese humo que desprendía la vela hacia la divinidad.

En cuanto a la superstición, ni siquiera tenemos que bucear en el tiempo para constatar su presencia en el cumpleaños. En países como Alemania o Eslovaquia aún persiste:

Si se le felicita al cumpleañero por adelantado, el cumpleañero podría morir antes de su cumpleaños. No es algo que esté demasiado difundido, pero sí existe esta superstición en Eslovaquia (Lucía Slobodníková, Eslovaquia).

Del testimonio podemos deducir que esta superstición está estrechamente ligada al pensamiento nuclear vinculado al umbral: no puedes celebrar algo que los dioses aún no te han concebido — completar ese año más de vida — porque se pueden enfadar y actuar contra ti.

En lo que respecta a otros elementos asociados a esta celebración podemos diferenciar los siguientes: las invitaciones; los amigos, los familiares, los seres queridos; los saludos; la sacudida (por ejemplo, el tirón de orejas), las dedicatorias; los regalos; el banquete (que incluye la comida, la tarta, el deseo, las velas, la canción y los aplausos). Aunque todos los elementos se dan prácticamente en todos los países - a excepción de las sacudidas, que por lo menos en la actualidad, no son tan generalizadas-, unos cobran mayor importancia que otros debido a sus valores, a su cultura.

Sobre las invitaciones podemos señalar que las nuevas tecnologías han hecho que ya no sea habitual entregar, de forma personal, una invitación en papel, sin embargo, en países en los que la invitación escrita era muy importante, como Australia o Reino Unido, aún se sigue manteniendo la importancia de este elemento, sobre todo por la necesidad de requerir de una respuesta dentro de un plazo fijado. Esto es enfatizado por Clare, ya que observa un comportamiento muy diferente en España, en donde, al parecer, no existe la costumbre de invitar y avisar con mucha antelación; en cambio, en Reino Unido se suele confirmar la asistencia una semana antes: 
Recuerdo que mi madre, por lo menos tres semanas antes, empezaba a hacer invitaciones. Siempre tenías que contestar a la invitación con una semana de antelación, tanto si ibas como si no ibas. Si no avisabas se veía como un gesto muy grosero (Clare, Reino Unido).

En cuanto a los invitados, existe bastante unanimidad entre los diferentes países: se invitaba a familiares, a amigos y también a compromisos (ley de reciprocidad). Casi todos los encuestados hacen hincapié que el paso a la adolescencia o al mundo adulto se suele celebrar por separado, especialmente el del aniversario número dieciocho. De esta forma, hay doble fiesta: una con la familia y otra con los amigos.

Otro de los componentes con el que nos encontramos es de la sacudida, muy habitual en los rituales de paso, no obstante, es el elemento más inusual, menos compartido si lo comparamos con el resto, aunque eso no quiera decir que no haya existido. Podemos diferenciar tres modalidades: el tirón de orejas (España, Italia, Hungría, Argentina), el azote en las nalgas (Alemania) y el hobl (Australia y Reino Unido) que consiste en zarandear al homenajeado cogiéndole de los pies y de las manos. En República Checa además uno se pone debajo del zarandeado, para que la espalda del homenajeado choque con la espalda del compañero que está agachado debajo de él.

Las tres modalidades señaladas tienen en común que se dan golpes de forma repetitiva (a excepción de la modalidad de hobl de Reino Unido y Australia), y que el número de golpes coincide con el número de años. Observamos así que el golpe parece tener un valor simbólico de despertar (aprender de los «golpes» que la vida te va dando con los años).

Algunos han visto en el tirón de orejas, en el caso español o italiano, la intención de hacer más sabio al homenajeado - las orejas grandes, propias de la vejez, simbolizarían ese conocimiento adquirido. Sin embargo, y revisando las otras costumbres, parece constituirse más bien como un acto que tiene como fin el «desadomecerse» del año anterior y despertar al nuevo año, lo que se puede interpretar como el valor de reprender para aprender: el homenajeado se lleva los «palos» que le corresponderían a su edad, ya que se trata de igualar los palos que la vida le tendría que haber dado (o los «palos» que tendría que haber aprendido [con el objeto de hacerle madurar], para poder sobrevivir). De hecho, ¿cuántas veces habremos visto a un adulto jalando de la oreja del niño como represalia?

En cuanto a los regalos, los besos, y dedicatorias se pueden considerar gestos de protección y de buenos deseos de los invitados hacia el cumpleañero. Por una parte, la dedicatoria - elemento fundamental en países como Australia o Inglaterra, al punto de que es inconcebible asistir a un cumpleaños sin una tarjeta o dedicatoria (pero sí se perdona ir sin otro presente), y el regalo se convierten en objetos de defensa - mágicosque acompañarán al cunpleañero en el futuro. Por otra, el beso parece infundir e impregnar en el propio cuerpo ese deseo de felicidad, de suerte, de seguridad.

Por su parte, el banquete posee una triple funcionalidad en el cumpleaños: un valor socializador, identitario y de poder: los invitados rodean al homenajeado, siendo ese círculo un medio de protección que está especialmente presente cuando se reúnen para que el homenajeado sople las velas.

Hemos comentado el significado y origen de los elementos que están en torno al banquete: las velas, la tarta, etc., haciendo referencia a los estudios de Ralph y Adelin Linton. Estos, como recordamos, señalan que ya estaban presentes en el mundo griego, exactamente en la fiesta de Atenea y señalaban su vinculación con la luna. Sin embargo, desde otra perspectiva más primitiva y general, bien podría hacer referencia a lo 
astrológico, recordemos la forma circular del stonehenge, la forma circular relacionada con esa idea de completar, de lo mágico. Las velas se podrían identificar con las luces de los astros, por lo tanto, con lo celestial, con lo divino.

\section{LA CANCIÓN}

La canción de cumpleaños por excelencia es sin duda la de Happy Birthday to you. De hecho, se trata de la canción más popular del mundo según el libro Guinness de los Records. Al parecer, la canción fue creada en 1893 en Kentucky, Estados Unidos, por dos hermanas que eran maestras: Patty y Mildred Hill, quienes modificaron la letra de una canción infantil suya que habían publicado ya (Good morning to all), junto con otras canciones, con el objeto de felicitar a una de sus alumnas que las había invitado a su festejo. A partir de ese entonces empezó a difundirse a nivel mundial.

Algunos países, sin embargo, poseen y recuerdan sus propias canciones tradicionales de cumpleaños. Tal es el caso, por ejemplo, de Eslovaquia ${ }^{2}$, Grecia, Hungría, Holanda, Polonia, Rumanía y Suecia. En todas esas canciones nos encontramos con las siguientes características: tono apelativo y entusiasta con el que se pide que el festejado viva mucho tiempo (la palabra junto a los recursos paralingüísticos se percibe como un deseo convertido en acto); es notable el interés y énfasis en mostrar alegría mediante el uso, de no solo de la entonación, sino de interjecciones como ¡hurra! o ¡viva! y los aplausos finales que acompañan a la canción (medios para alejar los males, lo que nos recuerda, de nuevo, a los actos mágicos de protección). Otra de las características que comparten es el uso de la repetición, concretamente del verbo «vivir», propia de las canciones mágicas y que además señala el propósito fundamental del ritual.

Por último, existen también otras canciones que, aunque no eran dedicadas al cumpleaños, se utilizaban para homenajear al cumpleañero; es el caso de España de:

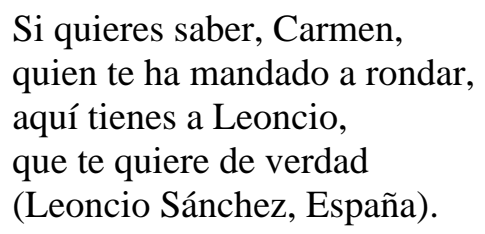

Concluimos este breve acercamiento al rito del cumpleaños con la esperanza de haber sido capaces de advertir la falta de estudios sobre este tema (pese a su antiguiedad y actualidad) y de haber logrado evidenciar su gran complejidad debido a sus profundas y desconocidas raíces.

Destacamos como una de las características más sobresalientes de la celebración del cumpleaños, en este rito de transición, su valor sincrético. Pues si bien está vinculado de forma clara con la astrología, también depende de otros aspectos que derivan de las creencias y temores humanos (relacionados con la muerte y su visión de la vida); lo que nos obliga atender a otros aspectos esenciales relacionados con la magia, la religión, la superstición en relación a ese umbral que señala la posible transición a «una puerta».

Precisamente, por su carácter de paso, nos encontramos con diversos formas, elementos y acciones protectoras: el círculo entorno al cumpleañero, las palabras mágicas selladas por el beso en las felicitaciones (e incluso las canciones típicas de cumpleaños

\footnotetext{
${ }^{2}$ Lucia Slobodníková nos cuenta que realmente la canción de Eslovaquia es de origen serbocroata, al parecer fue traída por los soldados de Eslovenia. También señala que no es muy popular, pues la cantan solamente los mayores.
} 
acompañadas de los aplausos) o los propios presentes como elementos físicos protectores, sus regalos y el banquete entre otros aspectos relacionados con este rito.

\section{BIBLIOGRAFÍA}

La Biblia. URL: <http://biblia.catholic.net/>

COROMINAS, J. y PASCUAL, J. A. (2001): Diccionario crítico etimológico castellano e hispano, Madrid, Gredos.

Enciclopedia Universal Ilustrada-americana (1913), Tomo XVI, Madrid, Espasa Calpe. Funk y Wagnalls (1972): Diccionario de folklore, mitología y leyenda, New York, Harper \& Row.

Herodoto DE HALICARnASO, (2000): Los nueve libros de la Historia, libro I, Educuibes Elaleph.com

Linton, Adelin y RALPH (1952): The Lore of Birthdays, New York, Omnigraphics.

ReAl de la ACADEMIa EsPañola, (2001): Diccionario de la Real Academia Española, (22. ${ }^{\text {a }}$ ed.), Madrid. URL: 〈http://www.rae.es/rae.html>

RINKOFF, Bárbara (1967): Birthday Parties Around the World, Hardcover, William Morrow.

YósIFOVA, Rositsa y PEDROSA, José Manuel (2009): «Costumbres y fiestas del pueblo búlgaro», El Jardín de la Voz, 9, serie de Culturas del Mundo, Biblioteca de Literatura oral y Cultura Popular.

FUENTES ORALES: INFORMANTES

- Anónimo. 50 años. Austria.

- Filip, Adriana. Rumanía.

- Gajlewicz, Karolina; 33 años. Polonia.

- Hansen, Ilse; 22 años. Holanda.

- Hudcovská, Jana; 31 años. Rep. Checa.

- Kovács, Marcs; 23 años. Hungría.

- Magali, 50 años. Francia.

- Mantovani, Elena; 38 años. Italia.

- Melcher, Betina. Alemania.

- Prochazkova, Katerina; 21 años. Rep. Checa.

- Rekilä, Laura. Finlandia.

- Ruotsila, Jasmiina. Finlandia.

- Ryan, Clare. Reino Unido.

- Sánchez, Leoncio, 90 años. España.

- Skoog, Catharina; 65 años. Suecia.

- Slobodníková, Lucía; 28 años. Eslovaquia.

Fecha de recepción: 29 de agosto de 2019

Fecha de aceptación: 2 de septiembre de 2019

$$
\text { 9 }
$$

